\title{
MILK Symposium review: Improving control of mastitis in dairy animals in Nepal*
}

\author{
Keshav Sah, ${ }^{1} \dagger \odot$ Prerana Karki, ${ }^{1} \odot$ Rima D. Shrestha, ${ }^{2} \ddagger \oplus$ Anil Sigdel, ${ }^{3} \odot$ Adegbola T. Adesogan, ${ }^{3}$ (1) \\ and Geoffrey E. Dahl ${ }^{3}$ (i) \\ ${ }^{1}$ Heifer International Nepal, Hattiban, Lalitpur 6043, Nepal \\ ${ }^{2}$ Himalayan College of Agricultural Sciences and Technology, Kathmandu 44600, Nepal \\ ${ }^{3}$ Department of Animal Sciences, University of Florida, Gainesville 32611
}

\section{ABSTRACT}

Dairy animals are an important source of income, food, and nutritional security, and improvements in the productivity of dairy animals substantially improve the wellbeing of smallholder dairy farmers. As in other developing countries, dairy animals are key for rural livelihoods in Nepal but often suffer from mastitis - a production disease causing economic losses to farmers, challenges to the dairy processing industry, and possible health hazards to consumers. Studies show that the prevalence of subclinical mastitis in Africa and Asia typically exceeds $50 \%$, threatening animal wellbeing, farmers, dairy processors, and consumers. We conducted a study in Nepal to develop a technology training package to control mastitis in dairy animals. Following identification of knowledge gaps, a technology package consisting of (1) developing good husbandry practices, implementing mastitis detection and control technologies; and (2) training technicians and farmers was implemented. A strategy was subsequently established to provide feedback to farmers in dairy cooperatives on the subclinical mastitis status of their cows. The package was applied in the mid-western region of Nepal. Six months after implementation, we observed a reduction in subclinical mastitis prevalence: from $55 \%$ (baseline) to $28 \%$ (endline; $\mathrm{n}=432$ ) in dairy cows and from $78 \%$ to $18 \%(\mathrm{n}=216)$ in buffalo. These positive study outcomes strongly suggest that the mastitis technology training package should be scaled across smallholder farmers within and beyond Nepal to control mastitis in dairy animals.

Received February 4, 2020.

Accepted July 23, 2020.

*Presented at the MILK Symposium: Improving Milk Production, Quality, and Safety in Developing Countries at the ADSA Annual Meeting, Cincinnati, Ohio, June 2019.

†Corresponding author: keshav.sah@heifer.org

$\ddagger$ Current address: One Health Institute, School of Veterinary Medicine, VetMed 3B, University of California-Davis, Davis, CA 95616 .
Key words: dairy animal, subclinical mastitis, technology training package

\section{INTRODUCTION}

Increases in the demand for milk in 2030 are projected to increase by $17 \%$ in Africa and by $32 \%$ in Asia relative to that in 2000 (Robinson and Pozzi, 2011). Nepali government policy documents (Government of Nepal, 2015) and rapid assessment of the gaps in dairy cattle production in the country (De Vries et al., 2020) identified some of the primary gaps for the dairy sector in Nepal; namely, improving milk yield, quality, and safety. Dairy is the most important livestock subsector in Nepal, contributing almost two-thirds to the livestock share of gross domestic product (ADAPT-Nepal, 2018). Cattle and buffalo are important dairy animals that contribute around 35 and $65 \%$, respectively, to national milk production in Nepal (FAO, 2018). Even though the subsistence dairy animal production system has been gradually transforming to commercial enterprises, particularly in peri-urban areas, the predominant system remains smallholder production, with 1 to 3 milking cows or buffaloes per household. In this system, dairy animal productivity is markedly low $(825 \mathrm{~L} /$ lactation in buffalo and $646 \mathrm{~L} /$ lactation in cow; FAO, 2018).

Mastitis is one of the greatest constraints to milk production globally. Studies have shown that the prevalence of subclinical mastitis (SCM) in Africa and Asia exceeds 50\% (FAO, 2014). The prevalence of SCM in dairy animals (cattle and buffalo) from smallholder farms to institutional farms in different parts of Nepal ranges from 13.6 to $60 \%$ (Shrestha and Bindari, 2012; Khanal and Pandit, 2013; Lamsal, 2018). Further, the prevalence of clinical mastitis (CM) is up to $56 \%$ in cattle and $52 \%$ in buffalo in Nepal (Dhakal and Subedi, 2002; Dhakal et al., 2007). It is widely recognized that SCM is an extensive problem in the dairy industry worldwide and it is of particular concern in developing countries (Abrahmsén et al., 2014). Subclinical mastitis is an inflammation of the udder in which cows do not 
show clinical symptoms but produce less milk of lower quality (Forsbäck et al., 2009). Management factors such as housing, nutrition, and milking methods have a major influence on the type of mastitis pathogen that can infect the mammary gland with varying degrees of infection (Radostits et al., 2007). When these factors are inadequate, mastitis-causing bacteria are able to pass along the teat canal, enter the udder, and initiate infection (Abrahmsén et al., 2014). Several studies have shown that SCM is economically more important than CM (Kader et al., 2003; Joshi and Gokhale 2006). This is because SCM is more difficult to diagnose and therefore usually persists longer in herds, causing greater production losses.

A high incidence of both CM and SCM is associated with poor adoption of good husbandry practices (GHP) and available mastitis control technologies (Ndyamukama, 2016). Little is known about the extent to which adoption of GHP and effective mastitis control strategies by Nepali farmers would reduce the prevalence of mastitis in dairy herds. Therefore, the primary objective of the project was to develop a technology package to control mastitis in dairy animals. The specific objectives were to (1) identify knowledge gaps about GHP; (2) develop a tailor-made training courses on GHP for Nepali smallholders, including mastitis detection and control technologies for farmers and technicians; and (3) test the effectiveness of the mastitis control technologies.

\section{MATERIALS AND METHODS}

\section{Study Sites and Animal Selection}

The project was implemented from January 2017 to February 2018 at 4 sites in 3 districts in the mid-western region of Nepal; 2 sites in Bardiya district and 1 site each in Dang and Surkhet districts (Figure 1). The districts are adjoining with similar weather conditions and a predominance of smallholder dairy farms that rear relatively low-producing dairy animals with little adherence to GHP. The site in Bardiya district is a flat area and dairy animals are mainly crossbred cows, whereas that in Surkhet district is a flat and lower hilly area with crossbred buffalo. The site in the Dang district is a flat area with both crossbred cows and buffalo. Mastitis has been more commonly reported in improved breeds or crossbred cattle, which typically have greater milk production than local breeds. Therefore, lactating cows (Holstein $\times$ Jersey crosses) and buffalo (Murrah $\times$ local crosses) were used to test the efficacy of postmilking teat dipping (PMTD; Wesen and Schultz, 1970) on SCS and milk electrical conductivity (EC).

\section{GHP Survey}

Implementation of GHP by the smallholder dairy farmers in the project areas was assessed through a baseline survey of 654 dairy animal-keeping households

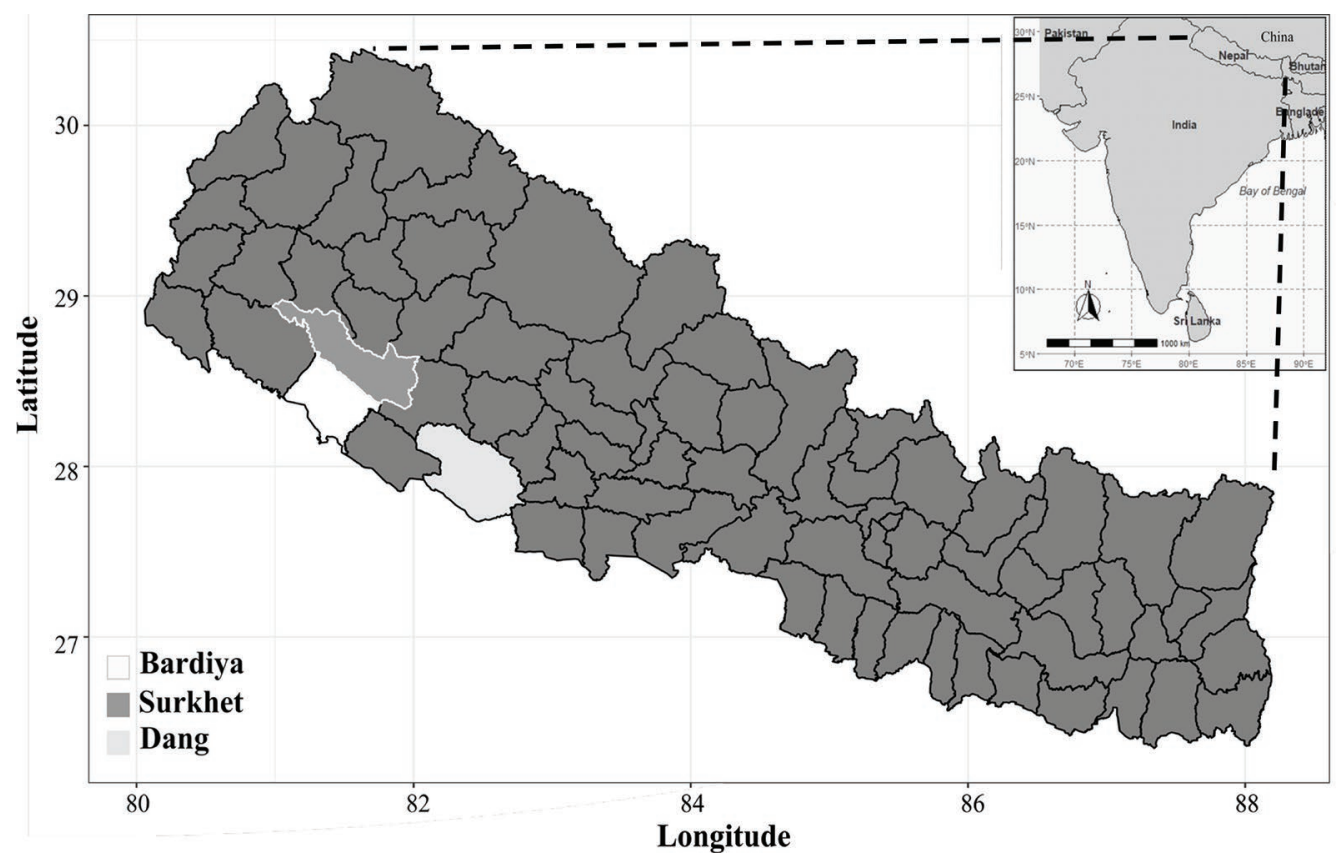

Figure 1. Map showing the districts of Nepal where this study was conducted: Bardiya, Surkhet, and Dang. Inset is the map of Nepal in South Asia. 
using a pretested semi-structured questionnaire. Criteria such as availability of farmers to participate, availability of crossbred milking animals, location of households, geography, and low level of GHP adoption (used no mastitis control technologies or other GHP) were considered when enrolling households into the study. This was to enable identification of gaps in knowledge, practices, and motivation, as well as documentation of major constraints to GHP adoption. The GHP factors assessed included barn management (e.g., type and condition of floor, bedding, manure pit), personal hygiene (e.g., hand washing and wiping before milking, cutting fingernails regularly), and animal hygiene (e.g., washing and wiping of udder, stripping milk before milk collection). Baseline prevalence of SCM was also assessed with the California Mastitis Test (CMT), as recommended by Ruegg and Reinemann (2002). Based on the baseline survey and SCM analysis, an appropriate GHP manual and training courses were prepared and provided in person using a "training of trainers" approach to technicians and extension workers. The latter trainees in turn provided training to farmers in person before the efficacy of mastitis control strategies was tested. The training covered animal, personnel, and environmental hygiene and mastitis detection and prevention.

\section{Experimental Study}

After the baseline survey and CMT test, an experimental study was conducted at all 4 sites. Site was taken as a blocking factor in the model. At each site, 4 samples were taken from the same animal at 4 time points. Therefore, a repeated mixed model design with blocking factors of site and parity was used to test the efficacy of mastitis control technologies including PMTD on SCM and EC of animals. Standard criteria for inclusion of dairy farmers included (1) ownership of at least one milking animal, (2) being a member of a dairy cooperative, and (3) interest in participating in the study. Criteria for inclusion of dairy animals were (1) physically healthy, (2) lactating, and (3) in the first 4 parities.

First, the CMT was used to assess the prevalence of SCM at all the study sites. Based on a positive or negative CMT, animals were randomized into an SCMpositive group (experiment 1) and an SCM-negative group (experiment 2). Within the SCM-positive and SCM-negative groups, animals were again randomized into treatment (PMTD) and control groups. The minimum number of cows and buffalo required to determine the efficacy of PMTD in each group was calculated using a power analysis with $\alpha=0.05$, power of test $=$ $80 \%$, and standardized effect size $=0.6$ (based on the standard deviation of milk yield and expectation that SCM would reduce daily milk yield by $20-30 \%$ ). Most (84\%) dairy farmers had 1 milking animal/household, and farmers in the control treatment had no access to antibiotics or other mastitis control technologies. Dairy farmers in the treatment group in experiment 1 ( $\mathrm{n}=70$ cows, 68 buffalo) and experiment $2(\mathrm{n}=68$ cows, 65 buffalo) were trained using the GHP manual, given povidone iodine and glycerin, and implemented PMTD daily on their cows for $3 \mathrm{mo}$, with monitoring by trained veterinary technicians. Dairy farmers in the control group in experiment 1 ( $\mathrm{n}=34$ cows, 34 buffalo) and experiment 2 ( $\mathrm{n}=34$ cows, 34 buffalo) were neither trained nor provided with reagents and no PMTD was implemented on their cows. For experiments 1 and 2 , milk samples were collected from all 4 sites from 2 species of dairy animal (buffalo and cows) across 4 time points. Milk samples were collected from dairy animals in their first, second, third, or fourth lactation. Even though the experiment was conducted from May through September, season was not specifically considered in the study because of the similarity of the weather during the period.

The efficacy of PMTD in cow and buffalo milk was determined by monitoring milk SCC and EC every 25 $\mathrm{d}$, with EC measured using a milk checker (electric conductivity tester; Everest Instrument Private Limited, Jaipur, Rajasthan, India; Hillerton and Walton, 1991). The EC cut-off value was $3.7 \mathrm{mS} / \mathrm{cm}$ for Murrah cross buffalo, but for cows it varied from 5.2 to 7.5 $\mathrm{mS} / \mathrm{cm}$ (Dhakal and Nagahata, 2018). We validated a cut-off value for the study animals before proceeding with the experiment because no published information was available on EC cut-off values for buffalo milk; the manufacturer-stipulated value for cow milk was $5.7 \mathrm{mS} /$ $\mathrm{cm}$ for the milk checker. Five milk samples (comprising CMT negative,,,++++++ from the baseline survey) were collected from each animal at each of the 4 study sites for $4 \mathrm{~d}$, and absolute EC values recorded. Median EC values for buffalo and cow milk were considered the cut-off point, and any value above the cut-off was considered indicative of SCM. This cut-off point was used to establish a system for 4 participating dairy cooperatives to provide feedback to farmers on the quality of their milk. Also, the animal was considered to have SCM based on an SCC value of $>120,000$ cells $/ \mathrm{mL}$. A milk checker was used to measure the cut-off value of SCC in those areas so that dairy cooperatives could inform farmers about the SCM in their milk samples.

At the end of the project, an endline survey and CMT were conducted 6 mo after the baseline survey to assess the prevalence of SCM and adoption of GHP on treatment and control groups in both CMT-positive and CMT-negative groups. 


\section{Statistical Analysis}

The baseline and endline survey and all other experimental data were saved in Excel 2016 (Microsoft Corp., Redmond, WA) and all analyses were conducted with $\mathrm{R}$ software (version 3.6.1; https://www.R-project.org/). Descriptive statistics were calculated for the survey results, and a paired $t$-test was performed to compare the baseline and endline survey in terms of GHP adoption and CMT results.

Before applying linear modeling, to make residuals normal, the SCC were log-transformed to obtain the SCS using the formula SCS $=\log _{2}(\mathrm{SCC} / 100,000)+3$ (VanRaden and Wiggans, 1991; Schutz, 1994; Schutz et al., 1995). A general linear mixed model was used to test the effects of PMTD on the counts of SCS and EC. A repeated mixed model with fixed effects of site, parity, time, experimental group, interaction of time and experimental group, and random effects of dairy animals nested within experimental group and random error terms was used. A multivariable repeated mixed model was used to test the effects of PMTD treatment on SCS and EC:

$$
\begin{aligned}
y_{i j k l}= & \operatorname{sites}_{i}+\text { parity }_{j}+\text { time }_{k}+\text { group }_{l}+\text { time }_{k} \\
& \times \text { group }_{l}+\operatorname{animals}_{\left(\text {group }_{l}\right)+e_{i j k l},}
\end{aligned}
$$

where $y_{i j k l}$ is the record of SCS and EC, sites $s_{i}$ is the study site in the experiment $(i=1,2,3,4)$, parity $_{j}$ is the parity in the model $(j=1,2,3,4)$, time $_{k}(k=$ $1,2,3,4)$ are the time points when EC and SCS are measured, group $_{l}$ are the experimental treatment and control groups $(l=1,2)$, animals $\left(\right.$ group $\left._{l}\right)$ is the number of animals nested within treatment and control groups, and $e_{i j k l}$ is the random residual effect. The SCS were transformed back into SCC for reporting the results. Significance was declared at $P<0.05$.

\section{RESULTS AND DISCUSSION}

In this study, we surveyed 654 households that primarily had 1 dairy animal at baseline. Among the 422/654 (64.5\%) households that Heifer International Nepal had worked with previously, $85.3 \%$ participated in the endline GHP survey.

\section{Demographics from the Baseline Survey}

In this study, most participants in the baseline survey were female $(\mathrm{n}=397,60.7 \%)$. Most of the participants $(\mathrm{n}=412,63 \%)$ were illiterate $(\mathrm{n}=212,32.4 \%)$ or had only attended informal classes $(\mathrm{n}=200,30.6 \%)$. Having more women responding in our study is consistent with the fact that women are responsible for the majority (61-75\%) of livestock production in Nepal (Joshi, 2000; IFAD, 2013); literacy rates were lower in our study sites than in the region overall (Paudel et al., 2009; CBS, 2012). Most participants came from elite castes (Brahmin-Chhetri, 74.6\%), who were the second highest population in the study areas (CBS, 2012), followers of the Hindu religion ( $\mathrm{n}=652,99.7 \%)$, and raised cows $(\mathrm{n}=458,70.1 \%)$, which are sacred animals in Hindu culture. Although buffalo farming for milk production is greater in Nepal overall than in the study sites, the study sites raised more cows for milk production (CBS, 2012). Each household had an average of 6.2 members per family, with an average of 1.8 children below the age of $18 \mathrm{yr}$. Compared with the national statistics report, the average household size (range: 4.75-5.18) in our study areas was higher (CBS, 2012). Cows in the participating households produced an average of $5.7 \mathrm{~L}$ of milk per day. Almost all farmers milked twice a day and the others milked once a day. Most ( $\mathrm{n}=394,60.4 \%)$ sold milk for income and most was sold on the private market $(\mathrm{n}=174,44.2 \%)$ without any milk testing, which increases the risk of disease transmission and likely affects the health of children and women. In the project areas, both cow and buffalo farming are popular, but people prefer to raise cows because they are easy to manage and produce more milk than buffaloes.

\section{GHP Survey}

Adoption of hygiene measures such as cutting of fingernails regularly and using a concrete or dry floor did not change after training (Table 1), but the practice of letting animals stand after milking decreased after training, for unknown reasons. Although some GHP such as washing the udder were already practiced by farmers, others were not. Udder washing was practiced by all farmers, but they lacked knowledge about washing the hands with soap and wiping the udder with towels before milking. Therefore, correct adoption of these practices increased after training.

Likewise, adoption of stripping of milk before milking increased after farmers were trained on GHP. Although eliciting behavior change to adopt new technologies can be a lengthy process, it is notable that within 6 mo, GHP training markedly increased awareness about SCM and led to adoption of important hygiene practices. Given the decrease in the SCM in the project area after adoption of GHP, regular training on GHP could greatly increase the adoption of these hygiene measures in the future.

Our survey did not find changes in daily cleaning of the shed; however, many farmers started using concrete floors in their milking shed (baseline: $48.2 \%$ vs. end- 
line: $51.8 \%$ ) and started keeping the floor dry (baseline: $47.9 \%$ vs. endline: $52.3 \%$ ) after GHP training. Because our study population comprised smallholder dairy farmers who mostly had 1 dairy animal per household, it was often too costly for them to change from mud to concrete floors. Also, these farmers are involved in other activities besides dairy farming, and cleaning the shed daily may have been too time consuming. Nevertheless, regular and sustained training on the importance of GHP in reducing mastitis and increasing milk yield and quality, which could subsequently increase the milk price, could lead to greater adoption of these practices.

Another important hygiene factor is the type of vessel used for milk collection and transportation. The GHP training increased the use of stainless steel pails, instead of plastic alternatives, for milking and transporting milk. Several studies have shown that the type of vessel used during milk collection and transportation affects milk quality (Chye et al., 2004; te Giffel and Wells-Bennik, 2010; Pandey et al., 2014). Before training, most of the farmers used plastic buckets for

Table 1. Effects of training on adoption of good husbandry practices (GHP) by smallholder dairy farmers across all four sites of project areas $^{1}$

\begin{tabular}{|c|c|c|}
\hline GHP and survey & $\begin{array}{c}\text { Total } \\
\text { number }\end{array}$ & $P$-value \\
\hline \multicolumn{3}{|c|}{ Use of a concrete floor } \\
\hline Baseline & 176 & \multirow{2}{*}{0.50} \\
\hline Endline & 189 & \\
\hline \multicolumn{3}{|l|}{ Use of a dry floor } \\
\hline Baseline & 227 & \multirow[t]{2}{*}{0.19} \\
\hline Endline & 249 & \\
\hline \multicolumn{3}{|c|}{ Wipe udder with cloth } \\
\hline Baseline & 15 & \multirow{2}{*}{0.00} \\
\hline Endline & 62 & \\
\hline \multicolumn{3}{|l|}{ Strip off milk } \\
\hline Baseline & 83 & \multirow[t]{2}{*}{0.00} \\
\hline Endline & 127 & \\
\hline \multicolumn{3}{|c|}{ Wash udder with soap } \\
\hline Baseline & 20 & \multirow[t]{2}{*}{0.00} \\
\hline Endline & 43 & \\
\hline \multicolumn{3}{|l|}{ Cut nails } \\
\hline Baseline & 339 & \multirow[t]{2}{*}{0.76} \\
\hline Endline & 349 & \\
\hline \multicolumn{3}{|c|}{ Wash hands with soap before milking } \\
\hline Baseline & 206 & \multirow{2}{*}{0.00} \\
\hline Endline & 251 & \\
\hline \multicolumn{3}{|c|}{ Let animals stand after milking } \\
\hline Baseline & 69 & \multirow[t]{2}{*}{0.00} \\
\hline Endline & 40 & \\
\hline \multicolumn{3}{|c|}{ Used stainless steel milk container } \\
\hline Baseline & 156 & \multirow[t]{2}{*}{0.00} \\
\hline Endline & 210 & \\
\hline \multicolumn{3}{|c|}{ Knowledge about subclinical mastitis } \\
\hline Baseline & 3 & \multirow[t]{2}{*}{0.00} \\
\hline Endline & 164 & \\
\hline
\end{tabular}

${ }^{1} \mathrm{~A}$ total of 654 households were included in the baseline survey, whereas only 558 households responded to the endline survey. Farmers in the survey areas were trained with regard to good dairy husbandry practices (GHP) for 6 mo. milk collection and transportation because they are cheap and readily available. However, the quality of milk degrades quickly in plastic containers (te Giffel and Wells-Bennik, 2010; Pandey et al., 2014), and they should be avoided.

In addition to barn and hygiene management, knowledge about SCM is an important factor that could improve adoption of GHP. The baseline survey showed that most dairy farmers were not aware of SCM before GHP training but most were aware after training (Table 1). Although most farmers knew about clinical mastitis, they were not aware of SCM and its effect on milk yield and quality, or that application of simple screening tests such as CMT could help them diagnose SCM at the farm level. The GHP training was effective at increasing awareness of farmers about SCM.

Before implementing the GHP training, only 3 of 654 farmers knew about SCM, and none had any knowledge about using screening tests such as CMT to detect SCM. Very few farmers (2-4\%) knew about mastitis control technologies such as PMTD. After training, all farmers $(\mathrm{n}=360)$ in the study knew about SCM and SCM detection technologies, and about half of the farmers started practicing them. This demonstrates the effectiveness of the short (6-mo) GHP training in educating farmers about SCM and its prevention.

\section{Prevalence of SCM}

The baseline survey of CMT showed high prevalences of SCM in cows $(55.0 \%)$ and in buffalo $(78.0 \%)$, which were reduced, after GHP training and adoption of the mastitis control technologies, to $28.0 \%$ in cows and $18.0 \%$ in buffalo. All 4 study sites had a prevalence of SCM $>50.0 \%$ in the baseline survey. Several studies have shown high prevalence of SCM in dairy cows $(29 / 63 ; 46.1 \%)$ and buffalo $(223 / 355 ; 62.8 \%)$ in different parts of Nepal (Dhakal and Subedi, 2002; Dhakal et al., 2007; Dahal et al., 2010; Shrestha and Bindari, 2012; Khanal and Pandit, 2013). The GHP training and adoption of mastitis control practices markedly reduced the prevalence of SCM in our project areas, particularly at site 1 (Figure 2). These results showed that training of farmers on GHP, SCM, and simple farmbased diagnostic techniques and prevention strategies such as CMT and PMTD can influence the knowledge, skills, and behavior of farmers in several ways that can increase milk yield and milk quality.

\section{Experimental Study}

The mean EC values for cow milk in the control group $(5.41 \pm 0.98 \mathrm{mS} / \mathrm{cm})$ was numerically and not statistically greater than those in the treatment group (5.38 


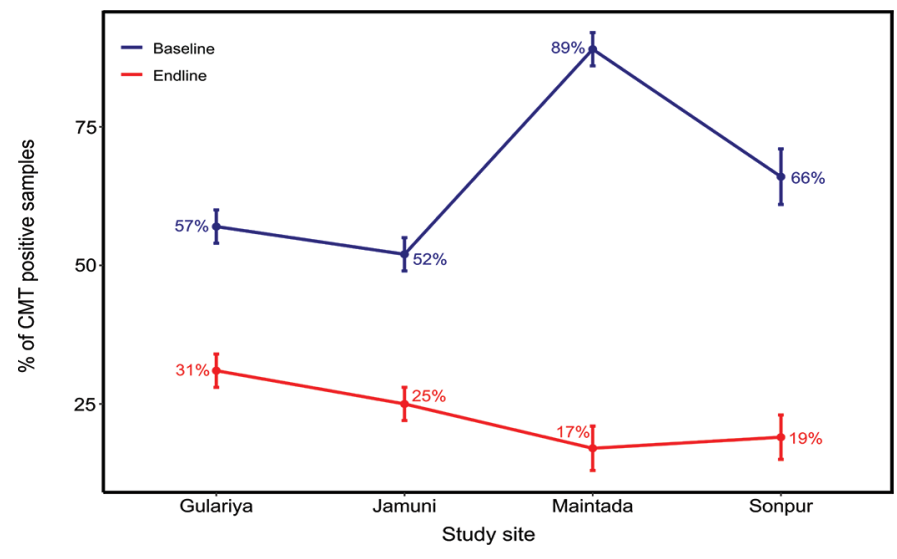

Figure 2. Prevalence of subclinical mastitis (SCM) as measured using the California Mastitis Test (CMT) during the baseline and endline surveys at 4 study sites (villages) in Nepal. Gulariya and Jamuni are in Bardiya district, Maintada is in Surkhet district, and Sonpur is in Dang district of Nepal. Baseline and endline surveys were done in March and November 2017, respectively. Owners were trained to adopt good husbandry practices. All sites had a significantly greater reduction in SCM $(P<0.000)$ at the endline survey. The error bars represent standard errors.

$\pm 0.85 \mathrm{mS} / \mathrm{cm})$. Similar results were observed in buffalo milk (mean: $3.80 \pm 0.74$ vs. $3.76 \pm 0.69 \mathrm{mS} / \mathrm{cm}$ ). The lack of differences between treatment and control animals may be due to the time that elapsed (up to 1 h) between milk collection and testing for EC, which may have influenced the results. Because EC measures the extent of damage of mammary cells and leakage of intracellular contents into the milk before cow reacts to infection, the SCC may be high in mastitic milk, even with a low EC value. We found a positive correlation $(\mathrm{r}=0.495 ; P<0.01)$ between EC and SCC, indicating that the combination of these 2 tests can be used together in the field for SCM diagnosis in smallholder dairy farms.

We were mainly interested in examining the effects of PMTD intervention in reducing the SCS in the SCMnegative group. It is important to note that PMTD is not typically effective at reducing SCS in cows that are already positive for SCM because PMTD is a preventive rather than curative approach. In SCM-negative cows, we were interested in examining the effects of treatment, time, and their interaction while considering the effects of site and parity on SCS and EC. We found that treatment (PMTD) reduced $(P<0.05)$ SCS in the SCM-negative group (Table 2). The PMTD intervention, however, did not have significant effect on EC $(P>0.05$; Table 3$)$. This is likely because of the low number of samples in the test and the delay between sampling and testing, which ranged from $20 \mathrm{~min}$ to 1 h. Overall, the study showed that PMTD reduced the SCC of the SCM-negative group, which indicates that the treatment was effective at preventing SCM.

\section{Establishment of Farmer Feedback Mechanism at Dairy Cooperatives}

A pilot study conducted to determine the EC cut-off points with the milk checker showed the conductivity cut-off points were $5.2 \mathrm{mS} / \mathrm{cm}$ for cows and $3.7 \mathrm{mS} /$ $\mathrm{cm}$ for buffalo; EC values above these thresholds indicated the presence of SCM in the dairy animals at the 4 sites. Visits of farmers between control and treatment groups were organized, in which they exchanged their experiences. This information was relayed to the 4 participating dairy cooperatives, who started advising their members to test milk samples for SCM. This encouraged farmers to improve overall GHP on dairy

Table 2. Effect of post-milking teat dip (PMTD) on SCS in California Mastitis Test-negative samples

\begin{tabular}{|c|c|c|c|c|c|}
\hline Variable $^{1}$ & Value & $\mathrm{SE}$ & df & $t$-value & $P$-value \\
\hline Intercept & 3.29694 & 0.16838 & 384 & 19.57981 & 0.00 \\
\hline Site 2 & -0.67385 & 0.18932 & 125 & -3.55922 & 0.00 \\
\hline Site 3 & -0.59858 & 0.14096 & 125 & -4.24617 & 0.00 \\
\hline Site 4 & -0.54499 & 0.14774 & 125 & -3.68864 & 0.00 \\
\hline Parity 2 & 0.15280 & 0.15227 & 125 & 1.00351 & 0.32 \\
\hline Parity 3 & 0.03663 & 0.15539 & 125 & 0.23575 & 0.81 \\
\hline Parity 4 & 0.08942 & 0.16401 & 125 & 0.54519 & 0.58 \\
\hline Time 2 & 0.19272 & 0.14080 & 384 & 1.36872 & 0.17 \\
\hline Time 3 & 0.19608 & 0.14142 & 384 & 1.38642 & 0.16 \\
\hline Time 4 & 0.16446 & 0.14142 & 384 & 1.16288 & 0.24 \\
\hline Intervention & -0.42948 & 0.16206 & 125 & -2.64999 & 0.00 \\
\hline Time 2: Intervention & 0.07334 & 0.20141 & 384 & 0.36413 & 0.71 \\
\hline Time 3: Intervention & 0.07148 & 0.20185 & 384 & 0.35416 & 0.72 \\
\hline Time 4: Intervention & 0.13767 & 0.20542 & 384 & 0.67021 & 0.50 \\
\hline
\end{tabular}

${ }^{1}$ Intercept is the reference value for Site 1, Parity 1, Time 1, Control, and interaction of Time 1 with Intervention. ${ }^{2}$ Milk samples were collected from 4 sites across the first 4 parities on 4 sampling dates (Time 1 to Time 4 ), each 1 mo apart.

${ }^{3}$ Intervention measures the effects of PMTD on SCS compared with the Control group. 
Table 3. Effect of post-milking teat dip (PMTD) on electrical conductivity (EC) in California Mastitis Testnegative samples

\begin{tabular}{|c|c|c|c|c|c|}
\hline Variable & Value & SE & df & $t$-value & $P$-value \\
\hline Intercept & 5.29772 & 0.12952 & 383 & 40.90129 & 0.00 \\
\hline Site 2 & -2.02198 & 0.14996 & 125 & -13.48275 & 0.00 \\
\hline Site 3 & -1.60310 & 0.11166 & 125 & -14.35639 & 0.00 \\
\hline Site 4 & -0.32178 & 0.11708 & 125 & -2.74817 & 0.00 \\
\hline Parity 2 & 0.01785 & 0.12049 & 125 & 0.14820 & 0.88 \\
\hline Parity 3 & 0.06366 & 0.12304 & 125 & 0.51742 & 0.60 \\
\hline Parity 4 & 0.17602 & 0.12979 & 125 & 1.35616 & 0.17 \\
\hline Time 2 & 0.00994 & 0.09779 & 383 & 0.10172 & 0.91 \\
\hline Time 3 & 0.25310 & 0.09824 & 383 & 2.57622 & 0.01 \\
\hline Time 4 & 0.05161 & 0.09824 & 383 & 0.52533 & 0.59 \\
\hline Intervention & 0.00258 & 0.11948 & 125 & 0.02159 & 0.98 \\
\hline Time 2: Intervention & -0.06379 & 0.13957 & 383 & -0.45706 & 0.64 \\
\hline Time 3: Intervention & -0.22079 & 0.13989 & 383 & -1.57835 & 0.11 \\
\hline Time 4: Intervention & 0.12584 & 0.14242 & 383 & 0.88358 & 0.37 \\
\hline
\end{tabular}

${ }^{1}$ Intercept is the reference value for Site 1, Parity 1, Time 1, Control, and interaction of Time 1 with Intervention. ${ }^{2}$ Milk samples were collected from 4 sites across the first 4 parities on 4 sampling dates (Time 1 to Time 4 ), each 1 mo apart.

${ }^{3}$ Intervention measures the effects of PMTD on EC compared with the Control group.

farms and improved the quality of milk received from farms by the dairy cooperatives.

The cost of CM including a veterinary treatment is estimated to be US $\$ 93$ per buffalo per lactation in Nepal (Dhakal and Thapa, 2002). This cost is higher than the cost of using the 3 diagnostic tools in the intervention package in this study (CMT, PMTD, and EC test). Therefore, the 3 tools were incorporated in extension programs implemented by Heifer International Nepal that targeted small dairy farmers to ensure wider use of the mastitis control technologies to reduce the milk loss. Subsequently, local veterinarians and cooperatives started supplying the materials used in mastitis diagnosis and control technologies at a fair price. Animal health workers started using the CMT technology for screening SCM at dairy households. Consequently, dairy farmers realized the benefits of timely mastitis detection and started paying animal health workers the for services. The teat dipping results of this study helped to motivate dairy farmers to practice teat dipping regularly. Dairy cooperatives also started using EC testing to provide feedback to farmers about the SCM status of their cows.

Women are significant actors in livestock systems, particularly in the dairy sector of Nepal. As in the mastitis study, targeting women to implement, adopt, and scale the mastitis control package will empower them by increasing their knowledge and skills and increase their incomes.

The technology package (GHP gap analysis and training with PMTD) reduced SCM prevalence after 6 mo of PMTD treatment in dairy smallholders. The markedly positive outcomes of this study strongly suggest that the mastitis technology package should be scaled among smallholder dairy farmers across and beyond Nepal. Involvement and training of dairy cooperatives will be key to maintaining farmer interest and scaling the package. The mastitis control package can be easily applied through integration and adoption by female and male farmers, depending on gender norms and the distribution of livestock management in the scaling regions.

\section{CONCLUSIONS}

Training in GHP increased adoption of hygienic practices among smallholders in Nepal and reduced the prevalence of SCM from 78.0 to $18.0 \%$ in buffalo and from 55.0 to $35.0 \%$ in dairy cows. The adoption of GHP along with PMTD reduced SCM in buffalo and cows that were SCM-negative but not in those that were SCM-positive. After the study ended, the mastitis technology package was scaled by Heifer International Nepal to about 10,000 dairy-keeping households in Nepal. This model is expected to be sustained due to the need for, benefits of, and cost effectiveness of the package. Our results strongly suggest that the package could be scaled up even further among smallholder dairy farmers across and beyond Nepal to increase milk quality and milk yield, thereby improving food security, nutrition, and health of women and children.

\section{ACKNOWLEDGMENTS}

This work was funded in whole or part by the United States Agency for International Development (USAID) Bureau for Food Security under Agreement \# AIDOAA-L-15-00003 as part of Feed the Future Innovation Lab for Livestock Systems. Travel to the meeting was 
funded by the American Dairy Science Association. Any opinions, findings, conclusions, or recommendations expressed here are those of the authors alone. The authors acknowledge the partnership and collaboration from the University of Florida (Gainesville); Heifer International Nepal (Kathmandu, Nepal); Department of Livestock Services (Hariharbhawan, Nepal); and Himalayan College of Agricultural Science and Technology (Kathmandu, Nepal). The authors have not stated any conflicts of interest.

\section{REFERENCES}

Abrahmsén, M., Y. Persson, B. M. Kanyima, and R. Båge. 2014. Prevalence of subclinical mastitis in dairy farms in urban and peri-urban areas of Kampala, Uganda. Trop. Anim. Health Prod. 46:99-105. https://doi.org/10.1007/s11250-013-0455-7.

ADAPT-Nepal. 2018. Economic burden evaluation of male calf born and unproductive dairy cattle in dairy farming in Nepal. Association for Development of Environment and People in Transition-Nepal. http://nddb.gov.np/download/publications/Final\%20 Report_economic\%20burden\%20of\%20male\%20calf.pdf.

Central Bureau of Statistics. 2012. A national report on National Population and Housing Census 2011. Accessed Feb. 3, 2020. http: //cbs.gov.np/wp-content/uploads/2012/11/National Report.pdf.

Chye, F. Y., A. Abdullah, and M. K. Ayob. 2004. Bacteriological quality and safety of raw milk in Malaysia. Food Microbiol. 21:535541. https://doi.org/10.1016/j.fm.2003.11.007.

Dahal, L. R., D. B. Nepali Karki, and R. Shah. 2010. Total bacterial counts of raw milk in Eastern Terai of Nepal. J. Agric. Environ. 11:46-50. https://doi.org/10.3126/aej.v11i0.3651.

De Vries, A., K. E. Kaylegian, and G. E. Dahl. 2020. MILK Symposium review: Improving the productivity, quality, and safety of milk in Rwanda and Nepal. J. Dairy Sci. 103: https://doi.org/10 $.3168 /$ jds.2020-18304

Dhakal, I. P., P. Dhakal, T. Koshihara, and H. Nagahata. 2007. Epidemiological and bacteriological survey of buffalo mastitis in Nepal. J. Vet. Med. Sci. 69:1241-1245. https://doi.org/10.1292/jvms.69 .1241 .

Dhakal, I. P., and H. Nagahata. 2018. Evaluation of mastitis related measures \& their applications to classify buffalo milk in Chitwan Nepal. J. Agric. Sci. Technol. 8:99-111.

Dhakal, I. P., and K. Subedi. 2002. Clinical mastitis in different breeds of cattle and buffaloes at Chitwan Nepal. J. Inst. Agric. Anim. Sci. 23:65-69.

Dhakal, I. P., and B. B. Thapa. 2002. Economic impact of clinical mastitis in the buffaloes in Nepal. Buffalo J. 2:225-234.

FAO. 2014. Impact of mastitis in small-scale dairy production system. Animal Production and Health Working Paper No. 13. Food and Agriculture Organization of the United Nations (FAO), Rome, Italy.

FAO. 2018. Nepal livestock data. Accessed Sep. 6, 2020. http://www .fao.org/faostat/en/\#data/QL.

Forsbäck, L., H. Lindmark-Månsson, A. Andrén, M. Åkerstedt, and K. Svennersten-Sjaunja. 2009. Udder quarter milk composition at different levels of somatic cell count in cow composite milk. Animal 3:710-717. https://doi.org/10.1017/S1751731109004042.

te Giffel, M. C., and M. H. J. Wells-Bennik. 2010. Good hygienic practice in milk production and processing. Pages 179-193 in Improving the Safety and Quality of Milk. Woodhead Publishing Series in Food Science, Technology and Nutrition. Mansel W. Griffiths, ed. Woodhead Publishing, Cambridge, UK. https://doi.org/10.1533/ 9781845699420.2.179.

Government of Nepal. 2015. Agriculture Development Strategy (ADS) 2015 to 2035. Ministry of Agricultural Development, Singhdurbur, Kathmandu, Nepal. http://extwprlegs1.fao.org/docs/pdf/ nep171433.pdf.
Hillerton, J. E., and A. W. Walton. 1991. Identification of subclinical mastitis with a hand-held electrical conductivity meter. Vet. Rec. 128:513-515. https://doi.org/10.1136/vr.128.22.513.

International Fund for Agricultural Development (IFAD). 2013 Rural poverty in Nepal. Accessed Jan. 31, 2020. http://www.ifad.org/ pub/ar/2013/e/index.htm.

Joshi, S. 2000. Counting women's work in the agricultural census of Nepal: A report. Gend. Technol. Dev. 4:255-270.

Joshi, S., and S. Gokhale. 2006. Status of mastitis as an emerging disease in improved and peri urban dairy farms in India. Ann. N. Y. Acad. Sci. 1081:74-83. https://doi.org/10.1196/annals.1373.007.

Kader, M. A., M. A. Samad, and S. Saha. 2003. Influence of host level factors on prevalence and economics of sub-clinical mastitis in dairy cows in Bangladesh. Indian J. Dairy Sci. 56:235-240.

Khanal, T., and A. Pandit. 2013. Assessment of sub-clinical mastitis and its associated risk factors in dairy livestock of Lamjung, Nepal. Int. J. Infect. Microbiol. 2:49-54. https://doi.org/10.3126/ijim .v2i2.8322.

Lamsal, P. 2018. Cattle hygiene status and its relation with subclinical mastitis: A study in commercial farms in Rampur Nepal. Int. J. Appl. Sci. Biotechnol. 6:252-254. https://doi.org/10.3126/ijasbt .v6i3.21180.

Ndyamukama, C. F. 2016. Evaluation of microbial contamination in milk of healthy and mastitic cow in selected districts in Tanzania. MS Diss. Sokoine University of Agriculture, Morogoro, Tanzania.

Pandey, N., A. Kumari, A. K. Varma, S. Sahu, and M. A. Akbar. 2014. Impact of applying hygienic practices at farm on bacteriological quality of raw milk. Vet. World 7:754-758. https://doi.org/ 10.14202/vetworld.2014.754-758.

Paudel, L. N., U. ter Meulen, C. Wollny, H. Dahal, and M. Gauly. 2009. Gender aspects in livestock farming: Pertinent issues for sustainable livestock development in Nepal. Livest. Res. Rural Dev. 21:40.

Radostits, O. M., C. C. Gay, K. W. Hinchcliff, and P. D. Constable. 2007. Veterinary Medicine: A Textbook of the Diseases of Cattle, Horses, Sheep, Pigs and Goats. 10th ed. Saunders Ltd., Spain.

Robinson, T. P., and F. Pozzi. 2011. Mapping supply and demand for animal-source foods to 2030. Animal Production and Health Working Paper No. 2. FAO, Rome, Italy.

Ruegg, P. L., and D. J. Reinemann. 2002. Milk quality and mastitis tests. University of Wisconsin, Madison. Accessed Mar. 17, 2018. https://milkquality.webhosting.cals.wisc.edu/wp-content/ uploads/sites/212/2011/09/milk-quality-and-mastitis-diagnostic -tests.pdf.

Schutz, M. M. 1994. Genetic evaluation of somatic cell scores for United States dairy cattle. J. Dairy Sci. 77:2113-2129. https://doi.org/ 10.3168/jds.S0022-0302(94)77154-X.

Schutz, M. M., P. M. VanRaden, G. R. Wiggans, and H. D. Norman. 1995. Standardization of lactation means of somatic cell scores for calculation of genetic evaluations. J. Dairy Sci. 78:1843-1854. https://doi.org/10.3168/jds.S0022-0302(95)76809-6.

Shrestha, S., and Y. R. Bindari. 2012. Prevalence of sub-clinical mastitis among dairy cattle in Bhaktapur district Nepal. Int. J. Agric. Biosci. 1:16-19.

VanRaden, P. M., and G. R. Wiggans. 1991. Derivation, calculation, and use of national animal model information. J. Dairy Sci. 74:2737-2746. https://doi.org/10.3168/jds.S0022-0302(91)78453 -1 .

Wesen, D. P., and L. H. Schultz. 1970. Effectiveness of a post-milking teat dip in preventing new udder infections. J. Dairy Sci. 53:13911403. https://doi.org/10.3168/jds.S0022-0302(70)86406-2.

\section{ORCIDS}

Keshav Sah @ https://orcid.org/0000-0002-1716-6010 Prerana Karki @ https://orcid.org/0000-0002-1487-7335

Rima D. Shrestha ๑ https://orcid.org/0000-0001-8770-4171

Anil Sigdel ๑ https://orcid.org/0000-0002-6188-8053

Adegbola T. Adesogan (1) https://orcid.org/0000-0003-1020-7526

Geoffrey E. Dahl ๑ https://orcid.org/0000-0002-2182-6317 